Transportation Research Part F: Traffic Psychology and Behaviour,

Volume 15, Issue 3, May 2012, Pages 272-278

\title{
An Observational Study of Driver Distraction in England
}

Mark J.M. Sullman

Department of Systems Engineering and Human Factors, Cranfield University, UK

Address for contact:

Dr Mark Sullman

Department of Systems Engineering and Human Factors

Cranfield University

Cranfield

Bedfordshire

MK43 0AL

UK.

Phone +44 1234758229

Email: M.Sullman@cranfield.ac.uk 


\begin{abstract}
This study set out to investigate the proportion of UK drivers who engage in some form of distracting behaviour whilst driving. Data were collected by roadside observation in six urban centres in the South of England. The observations took place on randomly selected roads at three different time periods during two consecutive Tuesdays. The data revealed that $14.4 \%$ of the 7,168 drivers observed were found to be engaged in a distracting activity. The most frequently observed distraction was talking to a passenger, followed by smoking and using a mobile phone. Younger drivers were significantly more likely to be distracted in general and by talking to passengers, while older drivers were less likely to be distracted by adjusting controls or using a mobile phone.
\end{abstract}

Keywords: Driver distraction, Distraction, Cell phone, Mobile phone, Crash risk, Observation 


\section{Introduction}

Driver distraction is now recognised as a contributing factor in at least a quarter of motor vehicle crashes (McEvoy, Stevenson \& Woodward, 2007; Stutts, Reinfurt, \& Rodgman, 2001; Wang, Knipling \& Goodman, 1996). This proportion, however, could increase, in line with the increased use of portable technologies such as smart phones and satellite navigation systems. Therefore it is extremely important that we have a clear understanding of the types of distractions drivers currently engage in, their prevalence and the types of drivers who are more likely to be distracted.

Driver distraction can be defined as any secondary activity that draws the driver's attention away from the main task of driving (Ranney, 1994). Although the research investigating the impact of distractions on driving performance is well advanced, the research measuring exposure to driver distractions is still in its infancy (McEvoy \& Stevenson, 2008). McEvoy and Stevenson (2008) identify four broad approaches to investigating this issue; cross sectional surveys, roadside observation, naturalistic observation and epidemiological approaches. Despite roadside observation being one of the four main methods for investigating drivers exposure to driver distraction, surprisingly few studies have investigated driver distraction using roadside observation and most of those that do exist have solely concentrated on the prevalence of one type of distracter, the mobile phone (e.g. Eby, Vivoda \& St Louis, 2006; Horberry, Bubnich, Hartley and Lamble, 2001; Knowles, Walter \& Buckle, 2008; McEvoy et al., 2007; Taylor, MacBean, Das \& Rosli, 2007; NHTSA, 2010). Nevertheless, there has also been some research which has observed more general distractions, but these have mostly been conducted amongst professional truck drivers (e.g. Hanowski, Hickman, Wierwille \& Keisler, 2007; Hanowski, Perez \& Dingus, 2005) or private vehicle drivers (Dingus et al., 2006) in order to look at critical incidents and the distractions which lead up to these critical incidents. There are currently only two peer reviewed studies which have looked at more general distraction amongst the general public.

In one of the two peer reviewed studies to look more broadly at the issue of driver distraction in car drivers, Stutts et al. (2005) installed video cameras into 70 cars in America to observe what distracted 
car drivers. They found that the drivers in their study spent around $30 \%$ of the total time the vehicle was moving engaged in some form of distracting activity. The most common distraction was conversing with passengers (15.32\%), followed by eating and drinking (4.61\%), smoking (1.55\%), and manipulating controls (1.35\%). They also found that although using a mobile phone while driving was one of the many distracters, it was only observed $1.30 \%$ of the time. Unfortunately this research only included 70 drivers, meaning that it would be difficult to generalise these results to the general public and that it was not possible to reliably test for age or gender differences. This type of research is also very expensive, reliant on technology and the good will of volunteers. There is also a strong likelihood that some experimenter effect may have contaminated their data, as the drivers knew that they were being monitored and may have altered their behaviour to some degree. This issue was clearly acknowledged by Stutts et al. when they reported that almost $22 \%$ of the drivers in their study reported having the equipment in their car altered their driving.

One way of reducing the experimenter effect is to conduct the observations from outside of the vehicle, unobtrusively. This was attempted by Johnson, Voas, Lacey, McKnight and Lange (2004) who analysed 40,000 high quality digital photographs of drivers passing through a New Jersey turnpike. They found that less than $5 \%$ of the 40,000 photographs showed evidence of distraction. However, in contrast to Stutts et al. (2005) they found using a mobile phone was the most commonly observed distraction, with one third of those drivers judged to be distracted observed to be using a mobile phone. Smoking was the second most commonly observed distraction, with eating/drinking and interacting with a passenger accounting for most of the rest.

As the research by Johnson et al. (2004) included large numbers of participants they were also able to test for age and gender differences. Surprisingly, they did not find any pattern for general distractions by age or gender. However, looking just at the use of mobile phones, Johnson et al. found that younger drivers $(<45)$ were more likely to be observed using a handheld mobile phone than older drivers. 
Overall the top five distractions observed were reasonably similar for both studies, but the prevalence and orders were slightly different. These differences may have been for several reasons, such as the angle of view the observers had or the fact that Stutts et al. (2005) had much richer data upon which to base their decisions (e.g. movements, long periods to view their behaviour and the ability to review situations/behaviours). An observational method which would allow the collection of more rich data, than that collected by Johnson et al. (2004), would be through the use of roadside observation in a similar way to which handheld mobile phone use has been observed (e.g. Horberry et al., 2001).

As there is very little peer reviewed research investigating the issue of driver distraction using roadside observation and none currently from the UK, the present study set out to investigate the proportion of UK drivers who engage in an observable in-car secondary task whilst driving. The research also investigated the relative frequencies of the secondary tasks or distractions and whether there were any age and gender differences. In order to provide information necessary for the development of interventions (e.g. education, enforcement) it is important to know the type of driver who is more likely to be distracted and the types of distracting behaviours that they are more likely to engage in.

\section{Method}

\subsection{Locations \& Timing}

Six urban centres in the south of England were chosen, based upon convenience. These were; Bedford, Hatfield, Gloucester, Luton, Leigh-on-Sea and London. The observational sites within each urban centre were selected with the aid of an online random number generator. In the smaller centres a map of the urban centre was obtained and every $30 \mathrm{mph}$ zone street within the city limits was given a number. Following this one random number was generated using an online random number generator and was matched to the corresponding road on the map. In the larger centres the first step was to number all the grid squares and a random number generator was used to select which grid square to use. Following this all $30 \mathrm{mph}$ roads in that grid were given a number and a random number generator 
was again used to select the site for the observations to take place. Only $30 \mathrm{mph}$ roads were selected to facilitate observation of the drivers.

All sites were observed by the same single observer at three different time periods (10-11am, 2-3pm and 5-6pm) on two consecutive Tuesdays, to allow comparison with previous research (Taylor et al., 2007) and to encapsulate both peak and non-peak traffic times. All observations took place at least $100 \mathrm{~m}$ from controlled intersections, meaning that the traffic was relatively free flowing. The study was carried out in the spring, so daylight and weather conditions allowed a clear view of the drivers on all occasions. The observers were all students trained in what constitutes each type of distraction.

\subsection{Procedure}

The data were collected via roadside observation using a clipboard, form and pen. The observer noted every vehicle that drove past and whether they were engaged in a secondary activity. The observer was positioned so that the cars and the drivers were clearly visible and that they were as unobtrusive as possible. In most cases the observer was not visible, in advance, to the motorist. In all occasions the traffic on the same side of the street (as the observer) coming towards the observer were observed. The definitions of driver distractions were established in advance using the distractions identified by Stutts et al. (2005) and Johnson et al. (2004), which were refined following 10 hours of pilot data collection in St Albans (Hertfordshire). The refinements simply involved making the definitions more precise, in order to reduce uncertainty. The distractions which were very infrequently observed were also moved into the "other" category (e.g. reading map, using a SatNav).

Each of the observational sessions lasted for 60 minutes and a total of six hours of observations took place in each urban centre. The approximate age of the driver $(<30,30-50$, $50+$ ), gender, and time of day were also noted. The age groups used were chosen to be in accordance with previous research measuring handheld mobile phone use (e.g. Knowles et al., 2008; McEvoy et al., 2007; Taylor et al., 2007; Young et al., 2010) and were fairly broad 
to try and reduce the problems associated with estimating age based upon physical appearance. Finally, observers could record multiple distractions for any given driver (e.g. smoking and talking to passengers).

This study was approved by the Ethics Committee of the University of Hertfordshire.

\subsection{Measures}

Definitions of the Distractions

Driving only: Driver is observed to be driving only.

Handheld mobile phone use: Driver is holding a mobile phone to their ear.

Manipulating a phone: Driver is holding a mobile phone in their hand whilst driving. This also includes visibly keying buttons in a manner to send a text message or dial a number.

Smoking: Holding a cigarette and smoking it whilst driving a vehicle. This includes smoking, lighting and extinguishing a cigarette.

Eating/ Drinking: The driver is holding or drinking some sort of beverage. Or, the driver is holding or eating food whilst driving.

Adjusting controls: The driver is leaning forward to manipulate the central controls inside the car (e.g. stereo, heating). 
Talking to passengers: Driver is having a conversation or interacting with another individual in the car. Evidence of this can be that the driver is turning their head towards the passenger to either listen or talk, or appears to be talking and often also gesturing.

Other: All other distractions which did not fit into any of the above categories were recorded as "other" by the observers. This included such things as: reading, blowing their nose, grooming, or using a satellite navigation device.

Using a handheld mobile phone while driving is illegal in the UK and if caught the driver faces a $£ 60$ fine and three points on their licence.

\subsection{Inter-Observer Reliability}

A 40 minute trial was undertaken to assess the inter-observer reliability. All six observers were asked to monitor a road in Hatfield, UK. The number of vehicles reported ranged from 88 to 90 . Tests for observer effects, using chi-square and specifying an exact match, found that there were no significant differences between observers for gender, smoking, adjusting controls, using a mobile phone or other distractions. Furthermore, there was $100 \%$ agreement for eating and drinking, neither of which were observed during the trial. There were, however, significant observer effects for age $\left(\chi^{2}(5,89)=23.6\right.$, $\mathrm{p}<0.01)$ and talking to a passenger $\left(\chi^{2}(5,89)=40.1, \mathrm{p}<0.001\right)$. These differences were due to two observers, who received additional training following this session and prior to the data collection proper.

\section{Results}

A total of 7,168 drivers were observed during the study. Table 1 shows the number and percentage of drivers observed engaged in each type of distraction, overall and by age, sex and time of day. The 
Table also presents a conglomeration of separate chi-square contingency tables, which were combined into one table in the interests of parsimony. Where significant differences were found, the standardised residuals were examined to identify which cells were responsible for the difference (those larger than 1.96 indicating that the observed frequency was significantly different from that which would have been expected if there were no association between the variables in question). Of the 7,168 drivers observed, $14.4 \%$ were seen to be involved in a distracting activity whilst driving. The most frequently observed distractions were talking to a passenger (7.4\%), using a mobile phone (2.2\%) and smoking (2.2\%). Eating and/or drinking were observed in $1.1 \%$ of drivers, followed by adjusting controls $(1.1 \%)$, with the "other" category containing the remaining $0.9 \%$.

\subsection{Driver distraction by Gender}

As illustrated in Table 1, the rates for participation in a secondary activity were exactly the same for males and females (14.4\%). In addition the most frequently observed distraction for both genders was talking to a passenger. The second most commonly observed distraction among males was using a mobile phone $(2.3 \%)$, while for females it was smoking (2.2\%). However, overall there were very strong similarities between female and male drivers for each identified distracter and consequently no significant differences were observed.

\subsection{Driver distraction by age group}

In all age groups most of the drivers were not engaged in a secondary activity (Table 1). There were, however, some apparent differences by age group. Engagement in secondary activities was found to be $17.7 \%$ for motorists under the age of $30,13.7 \%$ for drivers aged $30-50$ and $13.3 \%$ for drivers over the age of 50 years old. This shows a relatively clear decrease in distraction by age, which was statistically significant $\left(\chi^{2}(2,7167)=15.88, \mathrm{p}<0.001\right)$. An examination of the standardised residuals shows that those younger than 30 years old engaged in more distractions than would have been expected if age were unrelated to distraction. 
Table 1 also shows that the most frequently observed distraction in all three age groups was talking to a passenger. The second most frequently observed distraction for the two younger age groups was using a mobile phone, while it was smoking for the oldest age group. Using a mobile phone was the third most commonly observed distraction for the oldest age group, while smoking was third for the two younger age groups.

There were no significant differences by age for eating, smoking or "other". However, there were apparent differences in the use of a mobile phone $\left(\chi^{2}(2,7167)=8.41, p<0.05\right)$. The standardised residuals indicate that those older than 50 years old were observed using a handheld mobile phone less often than expected. There was also a statistically significant difference, by age group, for talking to passengers $\left(\chi^{2}(2,7167)=16.56, \mathrm{p}<0.001\right)$, with the youngest age group being observed talking to passengers relatively more often than expected and the middle age group (30-50 years old) being observed less often than expected. There was also less adjusting controls in the older age group than expected $\left(\chi^{2}(2,7167)=8.73, \mathrm{p}<0.05\right)$.

\subsection{Driver distraction by time of day}

The proportion of drivers who were driving only, compared with distracted drivers, during the three time periods measured are also presented in Table 1 . There was a significant difference for the three time periods $\left(\chi^{2}(2,7167)=6.26, p<0.05\right)$, which appeared to be due to more distractions in the morning, but the standardised residual was just under $1.96(+1.8)$.

Table 1 also shows the type of driver distraction by time of day. There were no significant time of day differences in the use of a mobile phone, eating/drinking, smoking, adjusting controls or other. However, there was a significant difference for interacting with passengers $\left(\chi^{2}(2,127167)=6.80, p\right.$ $<0.05)$, which was due to more interacting with passengers in the morning (10-11am) observation period. 
[Insert Table 1]

\section{Discussion}

The present study investigated the proportion of drivers in the south of England who were engaged in different types of distractions whilst driving. This found that overall $14.4 \%$ of the observed drivers were engaged in a distracting activity whilst driving. This is considerably lower than the $30 \%$ found by Stutts et al. (2005), but is considerably higher than the 5\% reported by Johnson et al. (2004). This may be related to the quality of the evidence (or richness of the data) the observers had to base their decisions upon. In Johnson et al.'s research they had still digital photographs, whereas in the present study the observers generally had a few seconds upon which to base their judgement and were able to observe some movement. In Stutts et al.'s research they had three hours of video evidence to use and had a close up view of the driver and what the drivers were doing. They could also pause or review any behaviour or movement they were unsure of, unlike the present study or that of Johnson et al. Therefore the quality of the data in Stutts et al.'s research was much higher than in the present study, while the richness of the data in the present study was much higher than in Johnson et al.'s research. Interestingly, Stutts et al. reported the highest level of distraction, followed by the present study and then Johnson et al. Therefore, based upon these three studies it appears that the richer the data source the higher the reported level of driver distraction. However, another possible explanation is that any discrepancies could be due to data collection method (in-vehicle cameras vs. road side observation vs. still photographs), the research design (longitudinal vs. cross sectional), or cultural differences (USA vs. UK).

Despite the different data collection methods, the present study also had some similarities with the two previous studies, regarding the types of distractions observed. The most frequently observed distractions in the present study (talking to a passenger, using a handheld mobile phone, smoking, eating or drinking and adjusting controls) were exactly the same as the five most common found by Stutts et al. (2005) and four of the five found by Johnson et al. (2004). The only difference between 
Johnson et al. and the present study was that their top five contained those categorised as "other" (where the coders could not identify the type of distraction or there was no more appropriate category) in place of adjusting controls. The higher proportion of distractions classified as "other" is probably again due to the difficulty in identifying what a driver is doing from a still photograph. However, although the top five distracters identified in the present study were also similar to those found by Stutts et al. and Johnson et al. the rank ordering differed between the three studies. This could be due to differences in the methodology, such as the sample size ( 70 vs. 7,168 vs. 40,000 ), data collection method (in-vehicle cameras vs. road side observation vs. still photographs), or the research design (longitudinal vs. cross sectional). However, the agreement between these three studies indicates that the five most common types of in-car distractions appear to be talking to passengers, using a mobile phone, smoking, eating/drinking and adjusting the controls (e.g. radio, climate controls).

The present research also found demographic differences in who was more likely to be distracted and the type of distraction. Younger drivers were significantly more likely to be distracted, particularly by talking to a passenger, while older drivers were less likely to be observed using a handheld mobile phone or adjusting controls. The finding that older drivers are less likely to use a mobile phone while driving supports previous observational research (e.g. Horberry et al., 2001; NHTSA, 2010; Taylor, MacBean, Das \& Rosli, 2007) and the results of questionnaire-based studies (e.g. Gras, Sullman, Cunill, Planes, Aymerich, \& Font-Mayolas, 2007; Pöysti, Rajalin \& Summala, 2005; Sullman \& Baas, 2002; Young \& Lenné, 2010). Furthermore, as was the case in Young and Lenné's research the present study identified no significant differences between the young and middle-age groups for handheld mobile phone use and older drivers were less likely to be observed adjusting controls (e.g. change a $\mathrm{CD}$ and climate control) than the other two age groups.

The fact that young drivers were the most often distracted is particularly concerning, as younger drivers are also more likely to be speeding and engaging in other violations (Gras, Sullman, Cunill, Planes \& Aymerich, 2006; Gras et al., 2007). Furthermore, this finding is also in agreement with more 
general road safety research which has reported that younger drivers have more negative attitudes to road safety (e.g. Iversen \& Rundmo, 2004; Rhodes \& Pivik, 2011). Therefore, targeting educational and enforcement resources specifically at younger drivers is again highlighted by the present study.

The present study also found that the younger age group were more likely to be observed talking to passengers. Perhaps this could be because the younger age group were more likely to have passengers than the middle and older age groups. At odds with this hypothesis is Young and Lenne's (2010) questionnaire based research which found no age or gender differences for passenger carriage. Unfortunately information regarding the presence of passengers in the vehicle was not collected in the current study. Therefore, future observational research should investigate this question. It should also be noted that although talking to a passenger has been treated as a distraction in the present study, and in previous research (e.g. Johnson et al., 2004; Stutts et al., 2005), there is also evidence that conversing with a passenger does not significantly reduce driver performance and can even alert the driver to hazards (Charlton, 2009).

The rate of mobile phone use found here (2.2\%) was higher than the $1.5-1.6 \%$ found in the two Australian studies (Horberry et al., 2001; Taylor et al., 2007), similar to the $1.9 \%$ found in London (Knowles et al., 2008), but was considerably lower than that the 5\% found in the National Occupant Protection Use Survey (NOPUS; NHTSA, 2010). However, one reason for the high NOPUS rate could be that in many of the 51 states monitored, using a handheld mobile phone is not illegal. Furthermore, as in a number of other studies (e.g. Eby et al., 2006; Knowles et al., 2008; Taylor et al., 2007; Young, Rudin-Brown \& Lenne, 2010), the observations for the NOPUS survey were carried out at controlled intersections where most of the drivers were stationary. As Stutts et al. (2005) found the strongest predictor of engaging in a distracting behaviour was being stationary, we would expect the present study to report a lower rate than the NOPUS study and Knowles et al.'s research. Furthermore, as this study collected data from moving vehicles only, it could be considered a better measure of risk, as operating a mobile phone (or other distracting activities) while stationary does not put the driver (or anyone else) at any greater risk of crash involvement at that particular moment. 
The present research also found no gender differences for driver distractions in general, or for any specific types of distractions. Although this finding is in agreement with the research by Johnson et al. (2004), the previous findings on mobile phone use are much less clear. A number of studies have reported that males use a handheld mobile phone more often (e.g. Horberry et al., 2001; Knowles et al., 2008), while one study found females use a mobile phone more often (Crammer, Mayer \& Ryan, 2007) and several have found no difference (Taylor et al., 2007; Townsend, 2006). Perhaps this inconsistency simply confirms that there is no real difference in mobile phone use between males and females, as found in the present study.

This study is one of only a very small number of studies which have observed all types of in-car driver distractions in situ. The findings of this research, more often than not, back up the results of questionnaire-based research, providing some degree of validation for their findings and other types of observational studies using different methodologies. One of the main strengths of using roadside observation is the high degree of ecological validity. That is, to say, what is being collected is what is actually happening on the road at that one time.

\subsection{Limitations}

The level of distracted drivers observed here is likely to be an underestimate of the true level of driver distraction, as only obvious in-car distractions could be observed. Therefore, any distractions which did not involve a visible action (e.g. talking on a mobile phone using a hands-free device or looking at road side advertising) could not be recorded using this method of data collection. Furthermore, it is also possible that a small number of the drivers who were recorded as talking to a passenger may have been talking on a hands-free device. However, it is unlikely to be a substantial proportion of the drivers, as research has shown drivers are significantly less likely to talk on a mobile phone when there is a passenger in the car (e.g. Johnson et al., 2004; Stutts et al., 2005). 
Another potential limitation of this study is that in some cases the driver may have noticed the observer and changed their driving behaviour. However, as the observer was as unobtrusive as possible and in most cases was not likely to have been noticed by the driver, this is unlikely to have greatly affected the data. Furthermore, the present findings can only be generalised to $30 \mathrm{mph}$ urban roads, as distractions may be different on highways and other road settings.

The interobserver trial demonstrated that there were no significant observer effects for any of the variables measured, except for age and talking to a passenger. In terms of age, this was not particularly surprising as the judgement of age from physical appearance is very subjective. Therefore, the age groups presented here should be thought of as approximate only. Another factor contributing to this finding was the fact that cars tended to arrive together, and so by the time the first car had been observed (and noted) the second car had also often passed by. As the research assistants did not work at precisely the same speed, they may not have always been observing exactly the same car in all cases. Furthermore, there were also a number of vehicles missed during the data collection proper, again due to the vehicles arriving together, making it impossible to reliable record them all. Although the research assistants reported that the number of vehicles missed was not high, future research should mitigate this issue by using a less time consuming data collection method, such as voice recorders or video. Future research should also investigate whether there were any differences according to the day of the week, as only Tuesdays were monitored in the present study.

\section{Acknowledgements}

This study was conducted while the author was working at the University of Hertfordshire. The author would like to thank the research assistants who collected the data: Tracy Knott, Claire Palmer, Bethan Kerslake, Stephanie Hartley, Moniel Patel, Arun Mahey, \& Elliot Ross. 


\section{References}

Charlton, S.G. (2009). Driving while conversing: Cell phones that distract and passengers who react. Accident Analysis and Prevention, 41, 160-173.

Cramer, S., Mayer, J., \& Ryan, S. (2007). College students use cell phones while driving more frequently than found in government study. Journal of American College Health, 56(2), 181184.

Dingus, T. A., Klauer, S.G., Neale, V. L., Petersen, A., Lee, S. E., Sudweeks, J., Perez, M. A., Hankey, J., Ramsey, D., Gupta, S., Bucher, C., Doerzaph, Z. R., Jermeland, J., \& Knipling, R.R. (2006). The 100-Car Naturalistic Driving Study, Phase II - Results of the 100-Car Field Experiment. NHSTA Report DOT HS 810 593.Washington, DC: NHSTA.

Eby, D.W., Vivoda, J.M., \& St Louis, R.M. (2006). Driver hand-held cellular phone use: A four-year analysis. Journal of Safety Research, 37, 261-265.

Gras, M. E., Sullman, M. J. M., Cunill, M., Planes, M., \& Aymerich, M. (2006). Spanish drivers and their aberrant driving behaviours. Transportation Research Part F, 9, 129- 137.

Gras, M. E., Sullman, M.J.M., Cunill, M., Planes, M., Aymerich, M., \& Font-Mayolas, S. (2007). Who uses a mobile phone when in Spain? Accident Analysis \& Prevention, 39, 347-355.

Hanwoski, R.J., Hickman, J.S., Wierwille, W.W., \& Keisler, A. (2007). A descriptive analysis of light vehicle-heavy vehicle interactions using in situ driving data. Accident Analysis \& Prevention, $39,169-179$.

Hanwoski, R.J., Perez, M.A., \& Dingus, T.A. (2005). Driver distraction in long-haul truck drivers. Transportation Research Part F, 8, 441-458.

Horberry, T., Bubnich, C., Hartley, L., \& Lamble (2001). Drivers' use of hand-held mobile phones in Western Australia. Transportation Research Part F, 4, 213-218.

Horrey, W.J., \& Lesch, M.F. (2009). Driver-initiated distractions: Examining strategic adaptation for in-vehicle task initiation. Accident Analysis \& Prevention, 41, 115-122.

Iversen, H., \& Rundmo, T. (2004). Attitudes towards traffic safety, driving behaviour and accident involvement among the Norwegian public. Ergonomics, 47, 555-572. 
Johnson, M.B., Voas, R.B., Lacey, J.H., McKnight, A.S., \& Lange, J.E. (2004). Living dangerously: Driver distraction at high speed. Traffic Injury Prevention, 5, 1-7.

Knowles, J., Walters, L.K., \& Buckle, G. (2008). Mobile phone and seat belt usage rates in London 2008. Transport Research Laboratory (PPR 364). Crowthorne, UK: TRL.

McEvoy, S., \& Stevenson, M. (2008). Measuring exposure to driver distraction. In M.A. Regan, J.D. Lee, \& K.L. Young (Eds.), Driver distraction: Theory, effects and mitigation (pp. 73-83). Boca Raton, FL: CRC.

McEvoy, S., Stevenson, M., \& Woodward, M. (2007). The contribution of passengers versus mobile phone use to motor vehicle crashes resulting in hospital attendance by the driver. Accident Analysis and Prevention, 39, 1170-1176.

National Highway Traffic Safety Administration. (2010). Driver electronic device use in 2009. NHSTA Report DOT HS 811 372. Washington: NHSTA.

Pöysti, L., Rajalin, S., \& Summala, H. (2005). Factors influencing the use of cellular (mobile) phone during driving and hazards while using it. Accident Analysis \& Prevention, 37, 47-51.

Rhodes, N., \& Pivik, K. (2011). Age and gender differences in risky driving: The roles of positive affect and risk perception. Accident Analysis \& Prevention, 43, 923-931.

Ranney, T. A. (1994). Models of driving behavior: A review of their evolution. Accident Analysis \& Prevention, 26, 733-750.

Stutts, J. C., Feaganes, J., R., Reinfurt, D., Rodgman, E., Hamlett, C., Gish, K., \& Staplin, L. (2005). Driver's Exposure to Distractions in their Natural Driving Environment. Accident Analysis and Prevention, 37, 1093-1101.

Stutts, J. C., Reinfurt, D. W., Staplin, L., \& Rodgman, E. A. (2001). The Role of Driver Distraction in Traffic Crashes. A Report prepared for the AAA Foundation for Traffic Safety, Washington, DC.

Sullman, M. J. M., \& Baas, P. (2004). Mobile phone use amongst New Zealand drivers. Transportation Research Part F, 7, 95-105.

Townsend, M. (2006). Motorists' use of hand held cell phones in New Zealand: An observational study. Accident Analysis and Prevention, 38, 748-750. 
Taylor, D.M.D., MacBean, C.E., Das, A., \& Rosli, R.M. (2007). Handheld mobile telephone use among Melbourne drivers. The Medical Journal of Australia, 187, 432-434.

Wang, J.-S., Knipling, R.R., \& Goodman, M.J. (1996). The role of driver inattention in crashes: New statistics from the 1995 Crashworthiness Data System. In $40^{\text {th }}$ Annual Proceedings Association for the Advancement of Automotive Medicine. (pp 377-392). Des Plaines, IA: AAAM.

Young, K.L., \& Lenné, M.G. (2010). Driver engagement in distracting activities and the strategies used to minimise risk. Safety Science, 48, 326-332.

Young, K.L., \& Regan, M.A. (2008). Driver distraction exposure research: A summary of findings. . In M.A. Regan, J.D. Lee, \& K.L. Young (Eds.), Driver distraction: Theory, effects and mitigation (pp. 319-331). Boca Raton, FL: CRC.

Young, K.L., Rudin-Brown, C.M., \& Lenné, M.G. (2010). Look who's talking! A roadside survey of drivers' cell phone use. Traffic Injury Prevention, 11, 555-560. 